\title{
INVESTIGATION ON MULTILEVEL INVERTER APPLIED FOR RAILWAYS TRACTION SYSTEMS: ECONOMICALLY EFFICIENT
}

\section{JAYDEEP LAKWAL, MANISHA DUBEY \& GAURAV GUPTA}

Department of Electrical Engineering, Maulana Azad National Institute of Technology, Bhopal, India

\begin{abstract}
Indian Railway's Electric Multiple Units (EMUs) has been adopted as a solution to the challenges for environmental hitches caused by the steam and diesel engines. In general, an electrified system of railways is provided with $25 \mathrm{kV}, 50$ $\mathrm{Hz}$ AC supply. It is fed to three phase, $400 \mathrm{~V}, 50 \mathrm{~Hz}$ traction motor with the used of step down transformer, converter and inverter. The traction in railways needs higher operation of voltage. It is to be accomplished by the use of recent introduced multilevel inverter (MLI). This research paper presents an implementation of multilevel inverter in Railway EMUs. Transistor clamped H-bridge (TCHB) MLI with small amount of semiconductor components and sole voltage source is used for implementation in Railways. Therefore, quantity of semiconductor components, expenditure and dimensions are condensed. The MLI which is proposed here includes an H-bridge clinched with a switch of bidirectional nature. It is efficient to produce a multilevel output voltage. This research paper presents a new switching method which has a very easy logical and arithmetic operation. The new switching method is general for any amount of steps/ levels. The performance and functional study of the MLI which is proposed is confirmed with the use of simulation software of MATLAB/SIMULINK. Comparison has been done for both the power circuits.

KEYWORDS: Transistor Clamped H-Bridge, PDPWM, MATLAB \& THD\%
\end{abstract}

Received: Jun 09, 2020; Accepted: Jun 29, 2020; Published: Jul 25, 2020; Paper Id.: IJMPERDJUN2020463

\section{INTRODUCTION}

Steam and engines with diesel were treated as a source of natural adversity on the wheels. Thus, there were many challenges and motive to get better efficiency and dependability of the steam traction drive. This shows the way to the electrification in railway systems. Traction drive with electric power has now been recognised as a proficient way of transmitting electric power to traction motors which can transport as much as 2 times the output tractive power of equivalent diesel engines. It is having higher power-to-weight share which results in quicker acceleration and high tractive force. Due to enhanced acceleration, additional stations can be served with fewer time lag and hence, creation to stoppage at the minor stations. It can be a further boost in the efficiency with the use of regenerative braking by the recycling of electrical power during slowing down of the train in the descending gradient. While sliding a gradient, electrical power can also be dissipated as a heat in the on-board resistors. Energetic optimization of regenerative braking for high speed railway systems is in [1-4]. On the whole an enhanced performance and least vibration results in more rapid, relaxing, smoother and peaceful journeys for the passenger.

The traction drives by electrical energy needs medium voltage and higher power operation and suppressed low frequency overload [5-7]. It can be achieved with the use of MLIs [8-13]. The traction transformer is step down the $25 \mathrm{kV}$ catenary voltage to a level suitable for electrical traction motors. This massive transformer reduces 
the efficiency; took huge weight, expenditure and large flooring space. It can be given that the MLIs can be directly coupled to higher supply of voltage and put down the output voltage. Hence, it extinguishes the requirement of transformer. As electric traction in railways need higher voltage operation. It can be realized by the series and/or parallel arrangement of various semi-conductor components. But because of the differences in their inbuilt characteristics, it may damage the components. This restraint can be conquering with the use of MLI. The output voltage of MLI has least harmonic contents (THD) as compare to two level conventional inverters. For such application, the MLI's output should bring away the limit for highest current and voltage THD (Total Harmonic Distortion \%) as listed in IEEE Std.519-1992.

The altering state of power requirement of the world leads to the advancement of various innovative inverter topologies and modern power semiconductor devices. MLI technology is one of them that have been mainly introduced for industrialized purpose having medium voltage and higher power demand. In late 1960, Technology of the multilevel inverter was invented. Numerous H-bridges were joined in series to furnish multilevel stepped waveform. This was known as cascaded H-bridge inverter [14-17]. In the similar year, a Flying Capacitor (FC) inverter was invented. According to a copyright that appears in 1975, the cascaded inverter provides a stairway waveform from numerous DC sources. In 1970s, Diode Clamped Converter (DCC) is invented [18-21]. Later on, in 1980, the DCC was also recognized as Neutral Point Clamped (NPC) inverter. It was so called, because in a 3- level inverter, the middle voltage is known as neutral point. As in 1981, Nabae et.al.introduced the first NPC PWM inverter. The CHB was once more reintroduced for the industrial function in the mid- 1990s. Likewise, FCs was utilized in medium voltage inverter in the early 1990s. In recent times, a lot of novel MLI topologies are coming up. Comprehensive reviews are mentioned in [22-25]. Stacking of inverters with lower voltage structure is in [26]. Step-Up Multilevel Inverter with a Single DC source [27]. A new E-type module for asymmetrical multilevel inverters is in (MLIs) [28]. Some of them are Switched-capacitor MLI (SCMLI) [29], Stacked cascaded multilevel inverter (SCMI) [30], cascaded matrix converter (CMC), hybrid FC - CHB, modular multilevel converter (MMC), mixed level hybrid multilevel cells, 3- level active NPC (3L-ANPC), soft switched multilevel inverters, transistor clamped converter (TCC), five level H-bridge NPC (5L - HNPC), hybrid NPC -CHB and many more.

There are varieties of techniques of modulation used in the MLIs as discussed in fig 1. Some of them are Multicarrier PWM, Selective Harmonic Elimination (SHE) [31-34], Sinusoidal PWM, Space Vector Modulation (SVM), a new space vector modulation method for extend the linear modulation range of an MLIs[35-37] and A Groebner Bases Theory for Selective Harmonic Elimination [38] etc.

Varieties of eye-catching features of the MLI are as follows [35-40]:

- Due to staircase waveforms of voltage output, $\partial v / \partial t$ and THD is reduced [39].

- As it can be switched at low frequency, result in better efficiency.

- Stresses on the motor bearings are reduced, due to lowering of common mode voltage. 


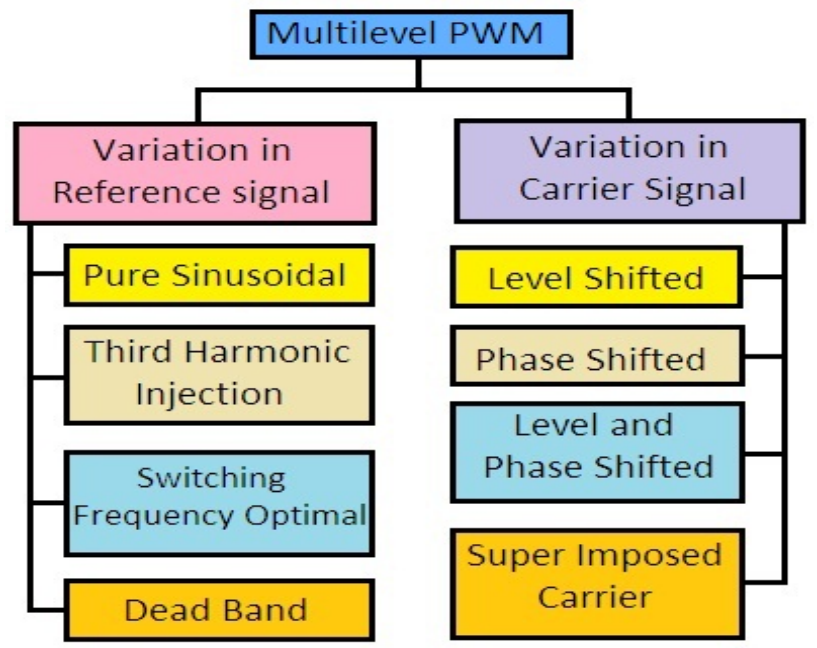

Figure 1: Categorization of Modulation Technique of Multicarrier PWM

On the contrary, they are having constraints and challenges with raise in the levels, there is raise in control difficulty and the disproportion problem of voltage arises. Even though four semiconductor components with reduced voltage ratings are used, each one must have its individual gate circuit, building it complex and costly. An aim of easy and rapid modulation techniques are also one of the technical issues. Several applications of the MLI consist of Wind energy conversion, Flexible Alternating Current Transmission System (FACTS), High voltage direct current (HVDC), Rolling mills, Conveyers, Fans, Compensations of reactive power, Transmission, Compressors, Railway electric traction, Hybrid Electric Vehicle. MLIs are not just for higher power applications like HVDC. But it can also be used for small power needs such as unconventional energy sources. These inverters can easily be interfaced with the unconventional energy sources like Wind energy conversion, PV cells [40-41], fuel cells. An efficiency enhancement scheme of a cascaded multilevel grid-connected inverter for renewable energy generation system is in [42]. The use of MLIs in electrical railway traction is a modern advancement. Thus, it makes contribution of power electronics toward a cleaner and greener earth.

In this manuscript, solution to this technical problem, an MLI with reduced amount of power semiconductor switching components and DC supply of voltage is introduced. It is a Transistor Clamped H-bridge (TCHB) MLI use solitary DC voltage supply adopted in [43]. In the proposed MLI, a supplementary circuit comes with four numbers of diode and a bidirectional switch present in the TCHB. Proposed power circuit replaces conventional inverter with multilevel inverter which is used in EMUs. While in the proposed MLI, the usage of amount of components and unwanted harmonics in the waveform of voltage output are minimized as compare to old conventional inverter. The MLI to be proposed will be able to extend for the use in grid joined wind energy system/ photo voltaic scheme and electrical hybrid vehicles and so on. Theoretical investigation, statistical simulation outcome shows the confirmation of the proposed transistor clamped H-bridge MLI.

Section II of the manuscript discusses EMU circuit topology with conventional inverter and EMU circuit used with MLI. Section III \& IV discusses loss calculation and widespread techniques of PWM modulation respectively. In Section V, the analyzed control is validated through simulation. Sections VI discuss the conclusion part.

\section{TOPOLOGY OF POWER CIRCUIT}

The power circuit of dual voltage EMU is suitable for operation under 1500V DC or $25 \mathrm{KV}$ AC system. Power circuit has following major equipments:Pantograph, Surge Arrestor, Voltage sensing device, AC DC changeover Switch, Vacuum 
Circuit Breaker, High Speed Circuit Breaker, Traction Transformer, DC link Capacitor and Converters (4 quadrant chopper, brake chopper and PWM Inverter). The block diagram of EMU power circuit is depicted in fig. 2

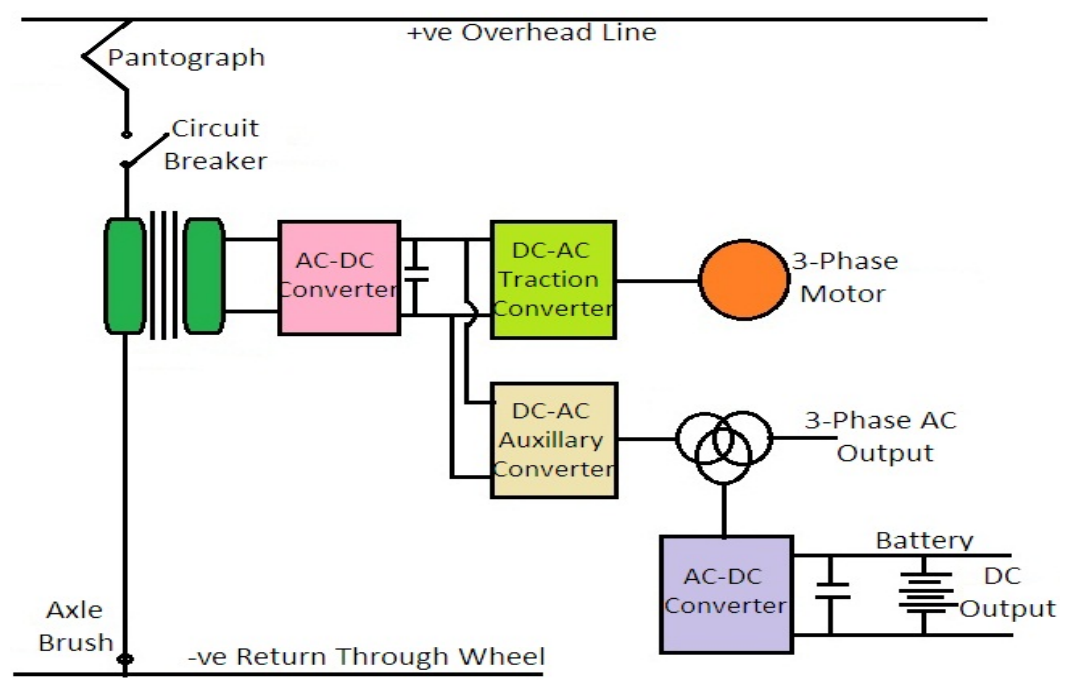

Figure 2: Generalised block drawing of EMU power circuit

\section{EMU POWER CIRCUIT WITH CONVENTIONAL INVERTER}

Inverter used in EMUs of Railway is conventional one, which is three phase conventional inverter. As shown from fig. 3. EMU power circuit is consists of single phase supply of $25 \mathrm{kv}$ AC fed to a transformer which is having dual secondary winding. Output of transformer is goes to AC to DC converter then fed to DC link. DC link consists of a capacitor and a inductor, series and parallel respectively. Output of DC link fed to DC to AC converter, which is three phase inverter. Output of inverter is goes through LC filter for making harmonic free supply to load.

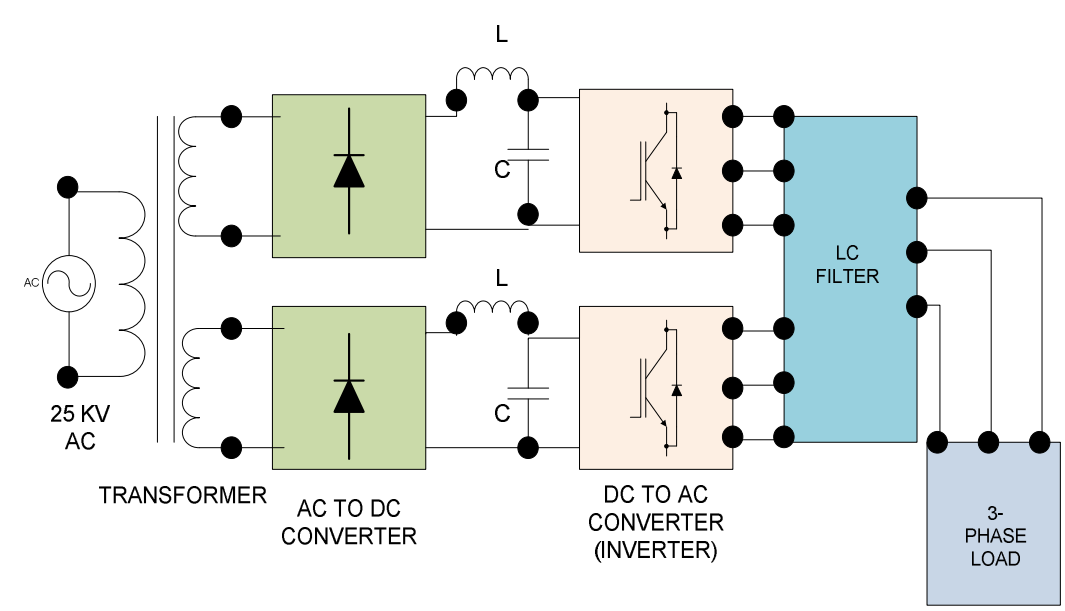

Figure 3: EMU power circuit with conventional inverter

\section{EMU POWER CIRCUIT WITH TRANSISTOR CLAMPED H-BRIDGE MULTILEVEL INVERTER}

MLI can be used in EMUs of railway. Three single phase MLI is used here for making three phase multilevel inverter as depicted in fig. 4. Proposed power circuit comes with single phase supply of $25 \mathrm{kv}$ AC fed to a transformer which is having dual secondary winding. Output of transformer is goes to AC to DC converter then fed to DC link. DC link consists of a capacitor and a inductor, series and parallel respectively. Output of DC link fed to DC to AC converters, which are three single phase multilevel inverters. Topology used in MLI is TCHB. Output of multilevel inverter is directly goes to load 
without using LC filter for making harmonic free supply to load.

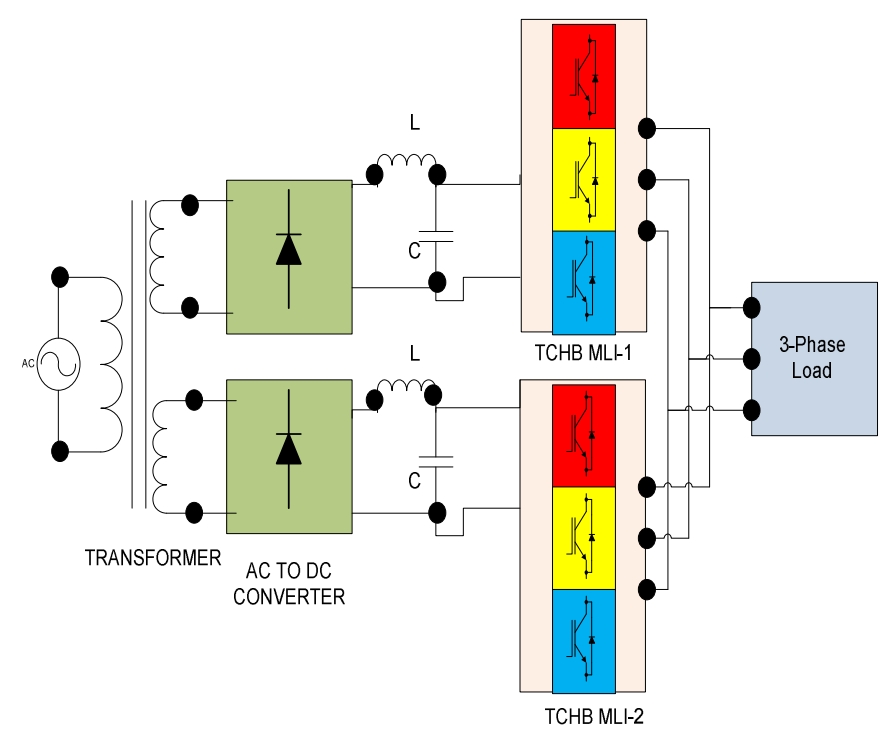

Figure 4: EMU power circuit with TCHB-MLI

\section{TRANSISTOR CLAMPED H-BRIDGE MULTILEVEL INVERTER}

Fig.5. is the all-purpose arrangement for the proposed multilevel inverter, comprise $\eta_{C}$ series-linked five-level TCHB unit [28]. Figure depicted the unit with an additional bidirectional IGBT switch linked between the capacitor middle point and the first leg of the H-bridge, generating five level voltage output $( \pm V d c, \pm 1 / 2 V d c, 0)$ based on switching patterns shown in Table I. The amount of power unit needed depends primarily on working voltage and manufacturing expenditure.

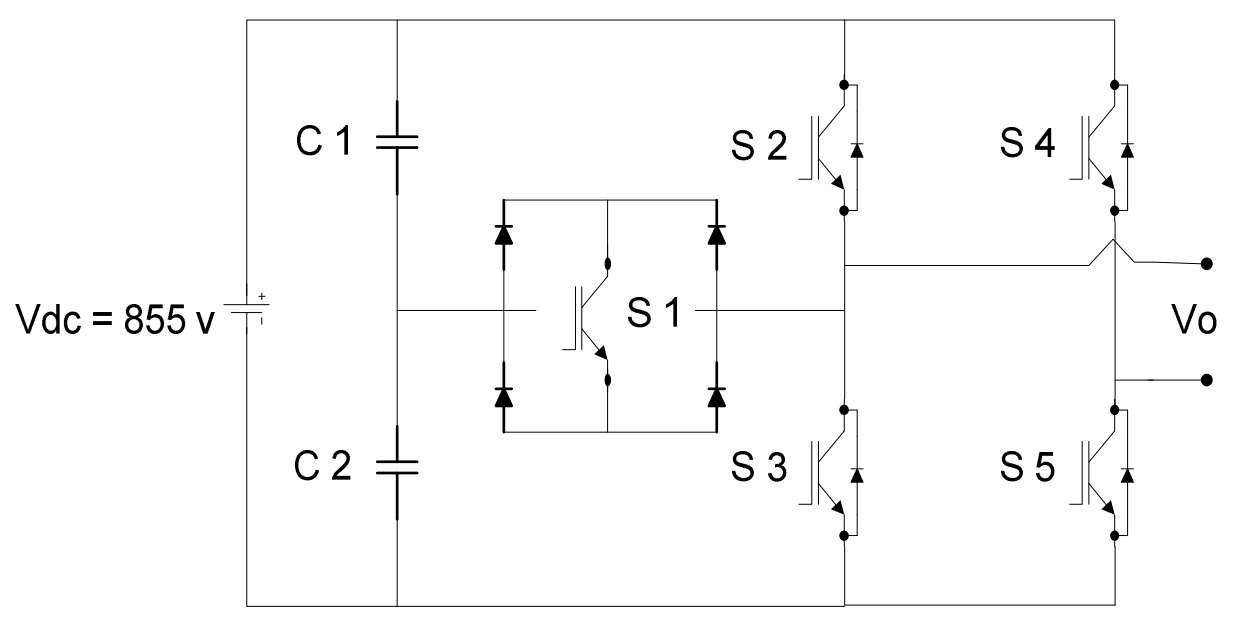

Figure 5: Circuit diagram of TCHB-MLI

Commonly, the highest level in the line \& phase voltages of the MLI which is proposed, based on $N_{C}$ units, is specified with the subsequent equations.

$$
\begin{aligned}
& \eta_{p}=N_{C}+1 \\
& \eta_{l}=N_{C}+1
\end{aligned}
$$


Table 1: Number of Switching components and Output Level for Transistor clamped H-bridge MLI

\begin{tabular}{|c|c|c|c|c|c|}
\hline$S_{1 a}$ & $S_{2 a}$ & $S_{3 a}$ & $S_{4 a}$ & $S_{5 a}$ & $V_{a o}$ \\
\hline 0 & 1 & 0 & 0 & 1 & $V$ \\
\hline 1 & 0 & 0 & 0 & 1 & $\frac{1}{2} V$ \\
\hline 0 & 0 or 1 & 1 or 0 & 0 or 1 & 1 or 0 & 0 \\
\hline 1 & 0 & 0 & 1 & 0 & $-V$ \\
\hline 0 & 0 & 1 & 1 & 0 & $-\frac{1}{2} V$ \\
\hline
\end{tabular}

Now, with suitable switching combinations, $S_{1 a}-S_{5 a}$ in Table I, voltage output of the unit, $V_{a o}$ can be taken as,

$$
\left.V_{a o}=V_{a o}\left(S_{5 a n}-S_{4 a n}\right)+\left[\frac{1}{2} S_{1 a n}+\left|S_{2 a n}-S_{5 a n}\right| \cdot \mid S_{3 a n}-S_{5 a n}\right]\right]
$$

\section{LOSS CALCULATION}

The losses of the multilevel inverter are to be calculated by the accumulation of losses incur by individual semiconductor components. Losses related with any semiconductor component can be normally described in three categories: 1) blocking state of the device; 2) conduction state of the device; 3) switching state of the device. Since current due to leakage is almost insignificant, the losses due to blocking states are negligible. As a result only losses due to switching and conduction are studied for the loss estimation for multilevel inverter.

\section{LOSSES DUE TO CONDUCTION}

Every switches fitted in the proposed design are conducting in bidirectional mode and blocking in unidirectional mode, as depicted in Fig. 1, the losses due to conduction are as follow:

$$
\begin{aligned}
& \rho_{a c, D}(t)=\left[V_{a D}+R_{a D} i_{a}(t)\right] i_{a}(t) \\
& \rho_{a c, T}(t)=\left[V_{a T}+R_{a T} i_{a}^{\alpha}(t)\right] i_{a}(t)
\end{aligned}
$$

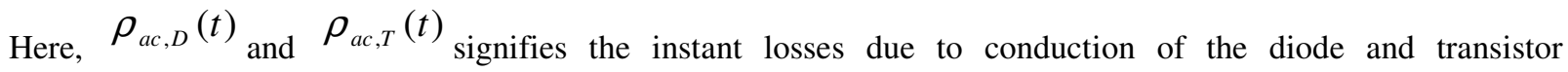
correspondingly. $\mathrm{V}_{\mathrm{aD}}$ and $\mathrm{V}_{\mathrm{aT}}$ are the drops in the ON-state voltage, while $\mathrm{R}_{\mathrm{aD}}$ and $\mathrm{R}_{\mathrm{aT}}$ are the corresponding ON-state resistances of diode and transistor, correspondingly and $\alpha$ is the constant directed by the characteristics of transistor.

\section{LOSSES DUE TO SWITCHING}

To determine the total losses during switching, a single switch is first calculated, and every individual loss due to switch is then accumulated to acquire the entire loss due to switching of MLI. Now, to determine the losses due to switching of a single switch, a linear estimate of current $\&$ voltage during time of switching is adopted.

Loss of energy during turning-on is: 


$$
\begin{aligned}
& E_{a o n, j}=\int_{0}^{t_{o n}} v_{a}(t) i_{a}(t) d t \\
& E_{a o n, j}=\int_{0}^{t_{o n}}\left[\left\{V_{a o, j} \frac{t_{a}}{t_{a o n}}\right\}\left\{-I \frac{\left(t_{a}-t_{a o n}\right)}{t_{a o n}}\right\}\right] t \\
& E_{a o n, j}=\frac{1}{6} V_{a o, j} I t_{a o n}
\end{aligned}
$$

Here,

$E_{\text {aon, }}$ losses during turn-on state of the $\mathrm{j}^{\text {th }}$ switch;

$\mathrm{t}_{\text {aon }}$ time of turn-on;

I current after the turning on of the switch;

$\mathrm{V}_{\mathrm{ao}, \mathrm{j}}$ voltage $\mathrm{j}^{\text {th }}$ switch wants to block.

In the same way, loss of energy during turning-off is:

$$
\begin{aligned}
& E_{a o f f, j}=\int_{0}^{t_{\text {off }}} v_{a}(t) i_{a}(t) d t \\
& E_{a o n, j}=\int_{0}^{t_{o f f}}\left[\left\{V_{a o, j} \frac{t_{a}}{t_{a o f f}}\right\}\left\{-I^{\prime} \frac{\left(t_{a}-t_{a o f f}\right)}{t_{a o f f}}\right\}\right] d t \\
& E_{a o n, j}=\frac{1}{6} V_{a o, j} I t_{a o f f}
\end{aligned}
$$

Here, $t_{\text {aoff }}$ is the time of turning-off for $\mathrm{j}^{\text {th }}$ switch and I' is the current prior to turning off of the switch.

\section{PROPOSED CONTROL AND MODULATION SCHEME}

\section{PROPOSED SCHEME OF CONTROLLING MLI}

In this subdivision, proposed scheme of controlling MLI is discussed. It is adopted in an approach that it is being capable to applied in all techniques of MLIs [34]-[36]. Figure 6 depicted the universal block diagram of scheme to be proposed of controlling MLI.

In the introduced MLI, let the amount of level in voltage which is in phase be $N_{\text {PLevel }}$. As the level ' 0 ' is vital, $N_{\text {PLevel }}$ is measured to be an odd one. Also, the amount of positive levels in the waveform $N$ to be:

$$
N=\frac{1}{2}\left[N_{\text {PLevel }}-1\right]
$$

The signal of modulation is of sinusoidal in nature with angular frequency $\mathrm{w}_{\text {ref }}$ and amplitude $\mathrm{A}_{\text {ref }}$. Signals of carrier are $2 \mathrm{~N}$ which are having triangular shapes for sinusoidal PWM. These signals of carrier have amplitude $\mathrm{A}_{\text {car }}$ and angular frequency $\mathrm{w}_{\text {car }}$. Carrier signals on top of zero levels are nominated as $\mathrm{f}_{\text {car }}^{+}$and those underneath zero level are 
nominated as $\mathrm{f}_{\text {car }}$.

At each instantaneous stage, each signal of carriers is compare with a reference of signal. For all signals of carrier on top of the zero level, each one assessment shows ' 1 ' if the carrier signal is lesser than modulation signal and ' 0 ' if not. For all signals of carrier underneath the zero level, each assessment shows ' 0 ' if the carrier signal is lesser than modulation signal and '-1' if not. Outcome so obtain are accumulated, produced a signal called a unique 'Aggregated Signal' chosen as $\mathrm{f}_{\text {agg. }}$. It has got noticed that signal so aggregated produces the identical waveform as the output estimated. Look up table and logic circuit is used for deriving the actual signal for switches from aggregated signal.

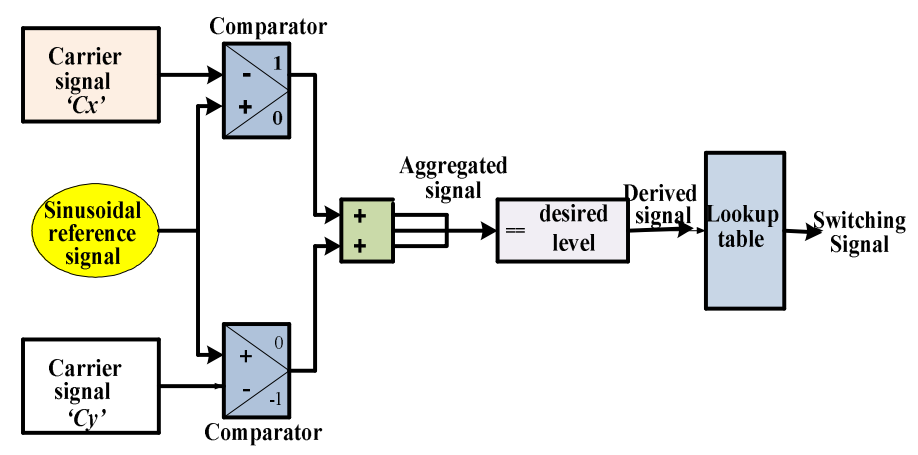

Figure 6: Universal block drawing of proposed scheme of controlling MLI

\section{SCHEME OF MODULATION}

It is normally established that the function of every MLI, with every switching tactic is to be allied with unwanted harmonic content inside its voltage output. There have numerous techniques of modulation for cascaded multilevel inverters are recorded in the literature [22]. Widely used method of modulation is the technique of multicarrier PWM. Categorization of Modulation Technique of Multicarrier PWM as depicted in Figure 1. Phase Disposition PWM (PDPWM) is one of the methods discussed out of specified categorization [24]. As a result of this PWM technique THD is reduced. This modulation technique use

Number of Signals of Carrier $=\left(\mathrm{N}_{\mathrm{L}}-1\right)(7)$

Here, $\mathrm{N}_{\mathrm{L}}$ is amount of levels

Signal of carriers is even with respect to zero level. Figure 7 depicted that reference signal which is sinusoidal in nature is compare with carrier.

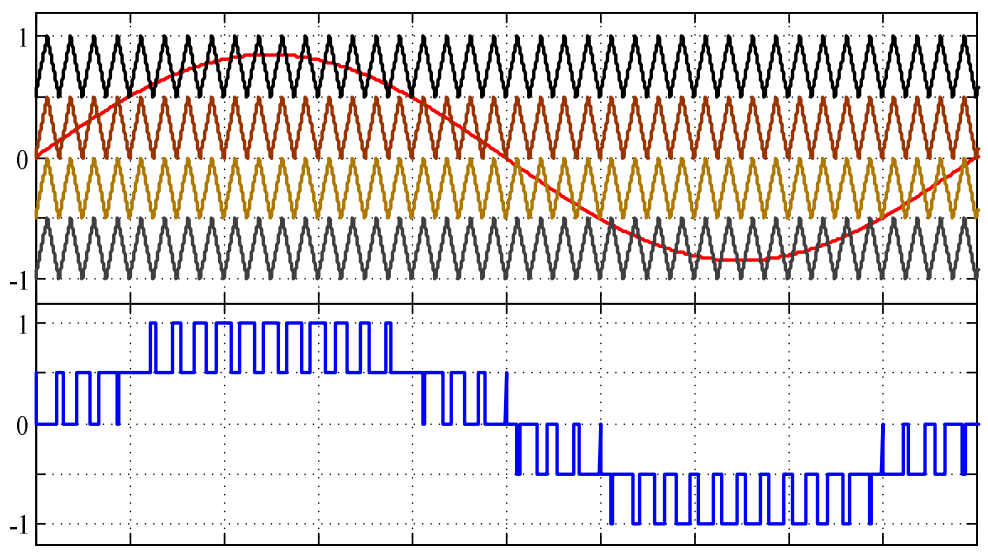

Figure 7: PDPWM and its Output 


\section{SIMULATION RESULTS}

The simulation results of EMU power circuit with conventional inverter and Transistor clamped H-bridge inverter is accessible by means of MATLAB/Simulink software. The strategy of PWM is in demand for generation of pulse. The IGBT switches are desired for its fast switching and power handling ability. 3- Phase Motor load is used for the simulation purpose. Control signals are generated with the use of this strategy of PWM.

The simulation circuit of MATLAB for proposed MLI consists of five IGBT switches for generation of 5-levels as depicted in figure 4. The waveform of output voltage of EMU power circuit with conventional inverter is depicted in figure 8. Results of harmonic investigation of output voltage of circuit with conventional inverter are depicted in Fig10. The waveform of output voltage of the EMU power circuit with Transistor clamped H-bridge MLI is depicted in the figure 9. Results of harmonic investigation of output voltage of circuit with Transistor clamped H-bridge MLI are depicted in Fig11. Fig 12 to fig 15 depicted various outputs of 3- Phase motor load at Torques of 0.1 to 50. A good quality of harmonic band can be achieved with the help of discussed PWM strategy. The proposed method produces gating signals and fed separately these signals to particular IGBTs. Merely single DC source is adopted for proposed configuration. The results of simulation verify that the configuration circuit is properly working. And, the waveforms of voltage output have 2-2-levels in positive area and negative area respectively and a '0' level. In Total there are 5-levels. Hence the 5-level MLI which is proposed is simulated fruitfully. In the sequential way, the results are below depicted.
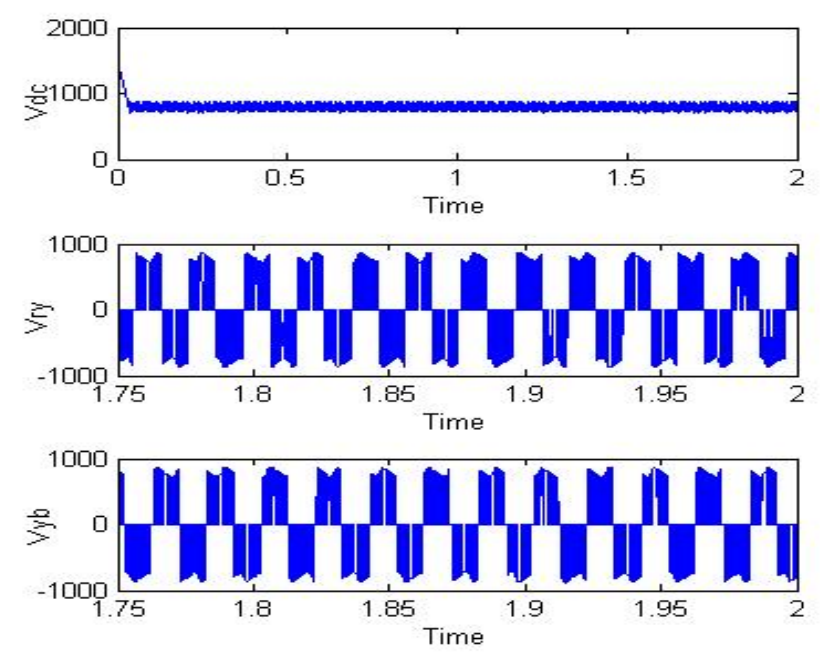

Figure 8: Voltage output of DC supply, R-Y phase and Y-B phase with conventional inverter 

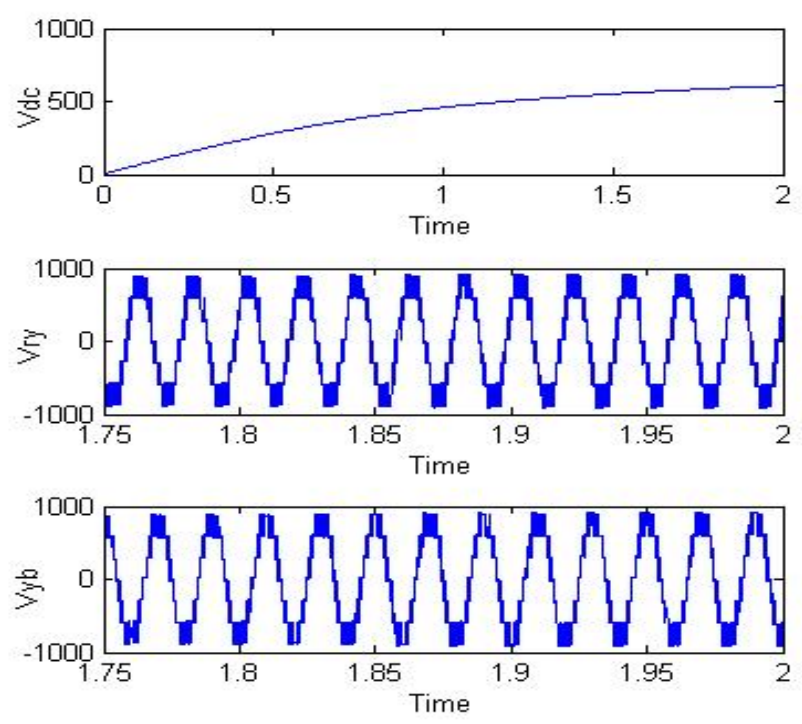

Figure 9: Voltage output of DC supply, R-Y phase and Y-B phase with multilevel inverter

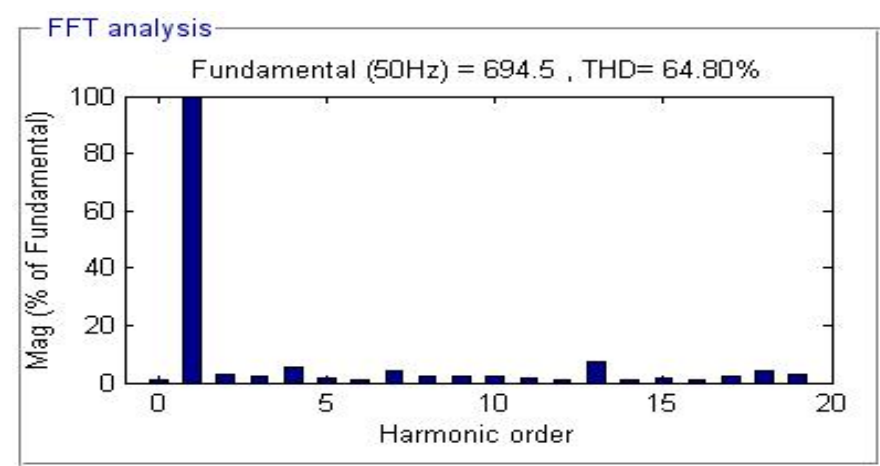

Figure 10: Harmonic analysis with conventional inverter

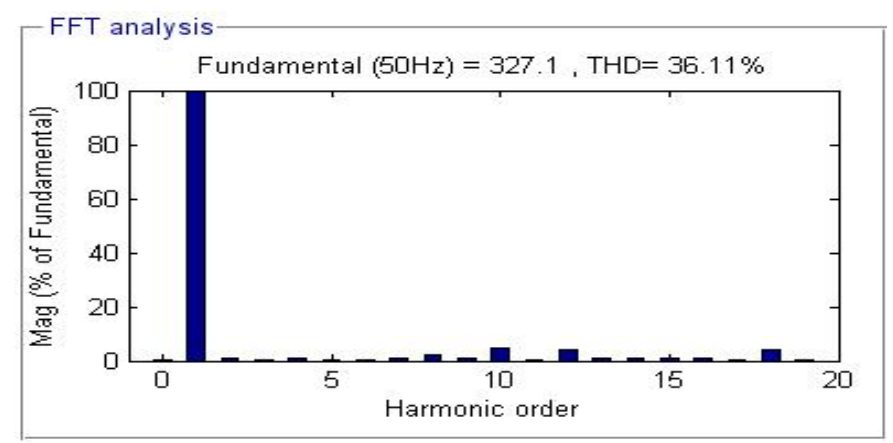

Figure 11: Harmonic analysis with multilevel inverter 

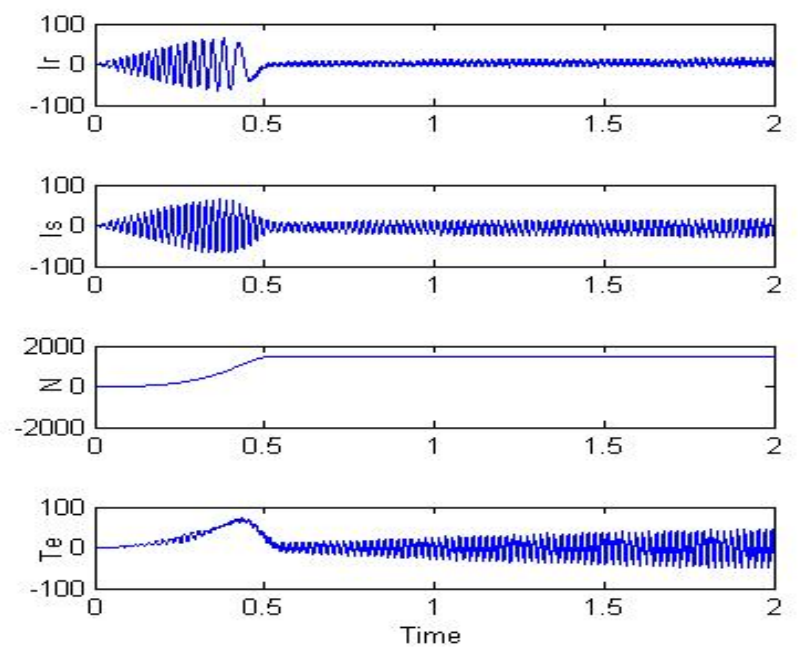

Figure 12: Various output for motor load with $T=0.1$
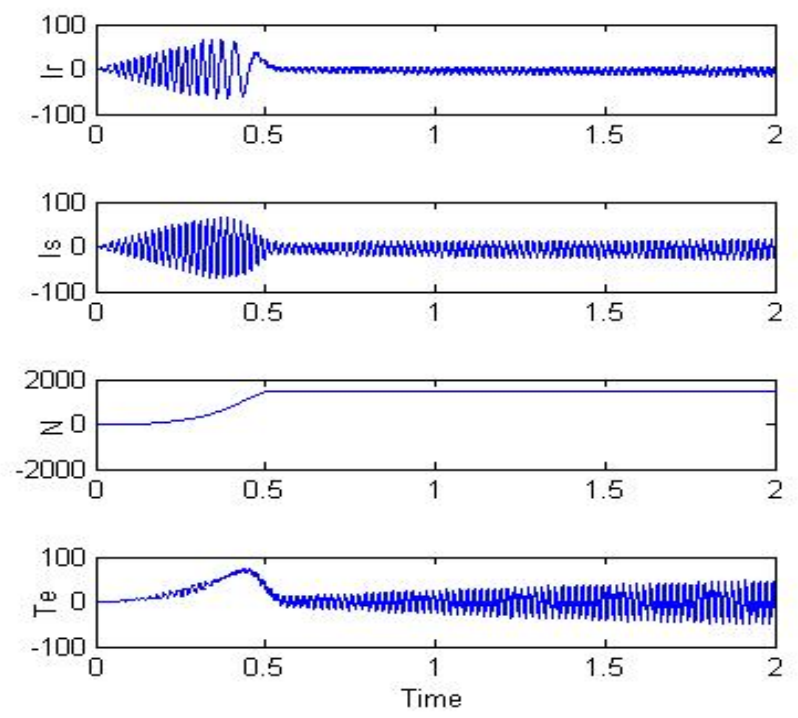

Figure 13: Various output for motor load with $T=1$ 

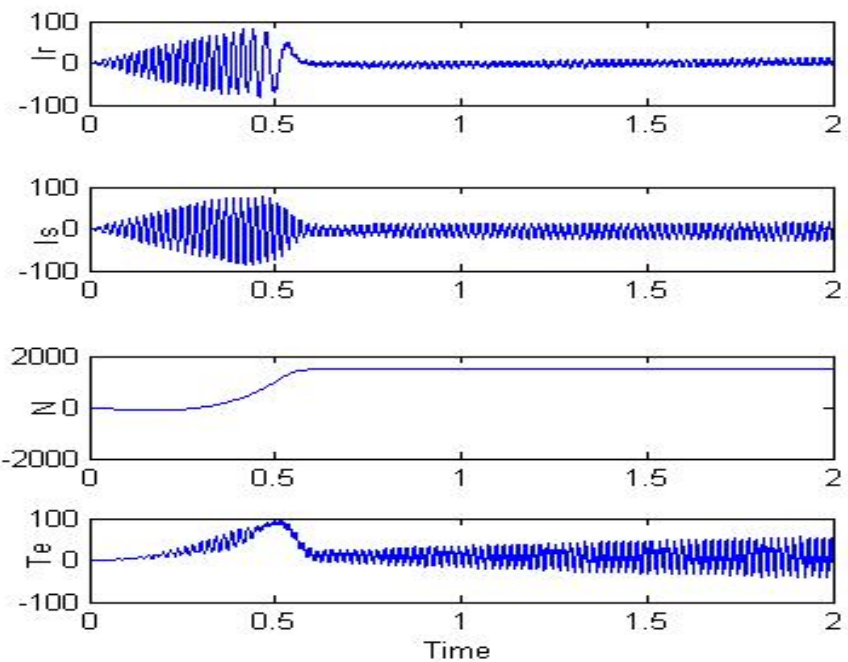

Figure 14: Various output for motor load with $\mathbf{T}=10$
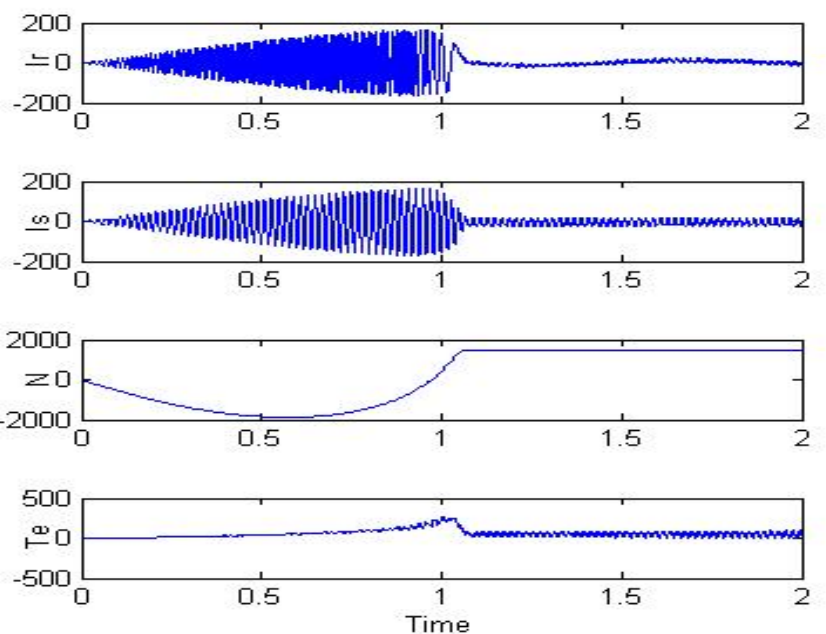

Figure 15: Various output for motor load with $\mathbf{T}=\mathbf{5 0}$

\section{CONCLUSIONS}

An EMU power circuit with Transistor clamped H-bridge MLI arrangement for Railway purpose uses single DC Sources have been carryout in the proposed paper. Initially, inverter configuration and switching approach were discussed. A voltage output is obtained with the introduction of PDPWM scheme for the reduction of unwanted harmonics. The proposed MLI arrangement has been simulated and the results of simulation are depicted. The THD \% values of waveforms of voltage output are also considered. The simplicity of spreading out and redundancy in the proposed MLI structure gives way for escalating the amount of output level. The MLI technique which is proposed produces waveform of output voltage with high-quality. It can be predicted that the contour of voltage output progressively converge to reference waveform of voltage output through escalating the amount of level modules. The results of this paper show that the proposed MLI configuration provides absolutely appropriate results for generating the necessary waveforms. Low unwanted harmonic content with output voltages can be achieved. 


\section{REFERENCES}

1. Zhigang Liu, Guinan Zhang, and Yicheng Liao," Stability Research of High-Speed Railway EMUs and Traction Network Cascade System Considering Impedance Matching”, IEEE Trans. Ind. Appl., vol. 52, no. 5, pp. 4315-4326, October. 2016.

2. AmedeoFrilli, Enrico Meli, Daniele Nocciolini, Luca Pugi, Andrea Rindi, "Energetic optimization of regenerative braking for high speed railway systems”, Energy conversion and Management,Vol No.129, pp.200-215, October 2016.

3. Guinan Zhang, Zhigang Liu, ShulongYao,Yicheng Liao, and Chuan Xiang, "Suppression of Low-Frequency Oscillation in Traction Network of High-Speed Railway Based on Auto-Disturbance Rejection Control”, IEEE Trans. On Transportation Elec, Vol. 2, NO. 2, pp. 244-255, June 2016.

4. Mohamed Z. Youssef, Konrad Woronowicz, Kunwar Aditya, Najath Abdul Azeez, and Sheldon S. Williamson, "Design and Development of an Efficient Multilevel DC/AC Traction Inverter for Railway Transportation Electrification”, IEEE Trans. on Power Elec., Vol. 31, No. 4, pp. 3036-3042, April 2016.

5. S. Bernet, “Recent developments for high power converter for industry and traction applications," IEEE Trans. Power Electron., vol. 15, no. 6,pp. 1102-1117, Nov. 2000.

6. M. D. Majrekar, P. K. Steimer, and T. A. Lipo, "Hybrid multilevel power conversion system: a competitive solution for highpower applications, "IEEE Trans. Ind. Appl., vol. 36, no. 3, pp. 834-841, May/Jun.2000.

7. J. Rodriguez, L. G. Franquelo, S. Kouro, J. I. Leon, R. C. Portillo, M. A. M. Prats, and M. A. Perez, "Multilevel converters: An enabling technology for high-power applications, " in Proc. IEEE, Vol. 97, No. 11, pp. 1786-1817, 2009.

8. J. Rodriguez, J.-S. Lai, and F. Z. Peng, “Multilevel inverters: A survey of topologies, controls, and applications,” IEEE Trans. Ind. Electron., vol. 49, pp. 724-738, Aug. 2002.

A. von Jouanne, S. Dai, and H. Zhang, "A multilevel inverter approach providing DC-link balancing, ride-through enhancement, and common-mode voltage elimination,” IEEE Trans. Ind. Electron., Vol. 49, No. 4, pp. 739-745, Aug. 2002.

9. S. Sirisukprasert, L. Jih-Sheng, and L. Tian-Hua, "Optimum harmonic reduction with a wide range of modulation indexes for multilevel converters," IEEE Trans.Ind. Electron., Vol. 49, No. 4, pp. 875-881, Aug. 2002.

10. S. A. Abu and W. Ming-yan, "Spectral analysis of hybrid capacitor-clamp cascade 13-level inverter," in International Conference on Industrial Technology (ICIT), pp. 271-276, 2006.

11. Deshmukh, S., and G. T. Thampi. "Transformative effect of e-commerce and m-commerce on national productivity in India'." International Journal of Applied Engineering Research and Development (IJAERD) 4.2 (2014): 65-80.

12. M. Schweizer, T. Friedli, and J. W. Kolar, "Comparative evaluation of advanced three-phase three-level inverter/converter topologies against two-level systems," IEEE Trans. Ind. Electron., Vol. 60, No. 12, pp. 5515-5527, Dec. 2013.

13. M. P. Aguirre, L. Calvino, and M. I. Valla, "Multilevel current-source inverter with FPGA control," IEEE Trans.Ind. Electron., Vol. 60, No. 1, pp. 3-10, Jan. 2013.

14. Y. Suresh, J. Venkataramanaiah, Anup Kumar Panda, C. Dhanamjayulu, P. Venugopal, "Investigation on cascade multilevel inverter with symmetric, asymmetric, hybrid and multi-cell configurations", Ain Shams Engineering Journal, Vol No.8, pp.263-276, October 2016.

15. L. M. Tobert, F. Z. Peng, T. Cunnyngham, and J. N. Chiasson, "Charge balance control schemes for cascade multi-level converter in hybrid electric vehicles,” IEEE Trans. Ind. Electron., vol. 49, no. 5, pp.1058-1064, Oct. 2002.

16. K. Chaniago, N. A. Rahim, and J. Selvaraj, "Novel fundamental-frequency-modulated modified H-bridge single-phase seven- 
level inverter for stand-alone photovoltaic system," InternaionalConference on Clean Energy andTechnology (CET), pp. 225230, 2011.

17. Nireekshana, T., and V. Ramesh Babu. "Design and Fabrication of Linear Induction Motor For Traction Application." International Journal of Electrical and Electronics Engineering (IJEEE) 6.6 (2017): 1-18.

18. J. Lakwal, D. M. Deshpande, A. Suresh, and A. Mittal, "Cascaded Multilevel Inverter Topologies for Photovoltaic Power Generation Systems", Int. J. of Chem. Tech. Research, vol. 5, no.2, pp. 1094-1100, April-June 2013.

19. M. Marchesoni and P. Tensa, "Diode-clamped multilevel converters: a practicable way to balance DC-link voltages," IEEE Trans. Ind. Electron.,vol. 49, no. 4, pp. 752-765, Aug. 2002.

20. X. Yuan and I. Barbi, “A New Diode Clamping Multilevel Inverter,”IEEE Trans. Power Electron., vol. 15, no. 4, pp. 711-718, Jul. 2000.

21. P. Zhiguo, P. F. Zheng, K. A. Corzine, V. R. Stefanovic, J. M. Leuthen, and S. Gataric, "Voltage balancing control of diode clamped multilevel inverter/rectifier system, ”IEEE Tran. Ind. Appl., Vol. 41, No. 6, pp. 1698-1706, Nov./Dec. 2005.

A. Bendre, S. Krstic, J. Vander Meer, and G. Venkataramanan, "Comparative evaluation of modulation algorithms for neutralpoint-clamped converters,” IEEETrans. Ind. Appl., Vol. 41, No. 2, pp. 634-643, Mar./Apr. 2005.

22. Natarajan Prabaharan, KaliannanPalanisamy, "A comprehensive review on reduced switch multilevel inverter topologies, modulation techniques and applications", Renewable and Sustainable Energy Reviews, Vol No.76, pp.1248-1282, April 2017.

23. Peeyush Kala, Sudha Arora, "A comprehensive study of classical and hybrid multilevel inverter topologiesfor renewable energy applications”, Renewable and Sustainable Energy Reviews, Vol No.76, pp.905-931, March 2017.

24. J. Venkataramanaiaha, Y. Suresha, Anup Kumar Pandab, “A review on symmetric, asymmetric, hybrid and single DC sources based multilevel inverter topologies”, Renewable and Sustainable Energy Reviews, Vol No.76, pp.788-812,March 2017.

25. Krishna Kumar Gupta, AlekhRanjan, Pallavee Bhatnagar, Lalit Kumar Sahu, and Shailendra Jain, "Multilevel Inverter Topologies With Reduced Device Count: A Review”, IEEE Tran. On Power Elec., Vol. 32, No. 1, pp. 135-151, January 2016.

26. Viju Nair R, Arun Rahul S, R. SudharshanKaarthik, Abhijit Kshirsagar, and K. Gopakumar, "Generation of Higher Number of Voltage Levels by Stacking Inverters of Lower Multilevel Structures With Low Voltage Devices for Drives”, IEEE Tran. On Power Elec., Vol. 32, No. 1, pp. 52-59, January 2017.

27. Amir Taghvaie, JafarAdabi, and Mohammad Rezanejad, "Circuit Topology and Operation of a Step-Up Multilevel Inverter With a Single DC Source”, IEEE Tran. on Ind. Elec., Vol. 63, No. 11, pp.6643-6652, November 2016.

28. Emad Samadaei, SayyedAsgharGholamian, AbdolrezaSheikholeslami, and JafarAdabi, "An Envelope Type (E-Type) Module: Asymmetric Multilevel Inverters With Reduced Components”, IEEE Tran. on Ind. Elec., Vol. 63, No. 11, pp.7148-7156, November 2016.

29. ElyasZamiri, NaserVosoughi, Seyed Hossein Hosseini, Member, IEEE, Reza Barzegarkhoo, and Mehran Sabahi, “A New Cascaded Switched-Capacitor Multilevel Inverter Based on Improved Series-Parallel Conversion With Less Number of Components", IEEE Tran. on Ind. Elec., Vol. 63, No. 6, pp.3582-3594, June 2016.

30. Y. Suresh, Anup Kumar Panda, "Investigation on stacked cascade multilevel inverter by employing single-phase transformers”, Engineering Science and Technology, an International Journal, Vol No.19, pp.894-903,January 2016.

31. Ye Zhan,YunWei Li, Navid R. Zargari, and ZhongyuanCheng,"Improved Selective Harmonics Elimination Scheme With Online Harmonic Compensation for High-Power PWM Converters", IEEE Tran. On Power Elec., Vol. 30, No. 7, July 2015. 
32. M. Balasubramonian and V. Rajamani, "Design and Real-Time Implementation of SHEPWM in Single-Phase Inverter Using Generalized Hopfield Neural Network”, IEEE Tran. on Ind. Elec., Vol. 61, No. 11, November 2014.

33. M. S. A. Dahidah and V. G. Agelidis, "Selective harmonic elimination PWM control for cascaded multilevel voltage source converters: A generalized formula," IEEE Trans.Power Electron., Vol. 23, No. 4, pp. 1620-1630, Jul. 2008.

34. J. R. Wells, G. Xin, P. L. Chapman, P. T. Krein, and B. M. Nee, "Modulation-based harmonic elimination," IEEETrans. Power Electron., Vol. 22, No. 1, pp. 336-340, Jan. 2007.

35. R. M. Valan, P. S. Manoharan, and A. Ravi, "Simulation and an experimental investigation of SVPWM technique on a multilevel voltage source inverter for photovoltaic systems," International Journal of Electrical Power \&Energy Systems, Vol. 52, pp. 116-131, Nov. 2013.

36. Arun Rahul S, SumitPramanick, R. SudharshanKaarthik, K. Gopakumar, and FredeBlaabjerg, "Extending the Linear Modulation Range to the Full Base Speed Using a Single DC-Link Multilevel Inverter With Capacitor-Fed H-Bridges for IM Drives", IEEE Tran. On Power Elec., Vol. 32, No. 7, pp. 5450-5458, July 2017.

37. Arun Rahul S, SumitPramanick, Mathews Boby, K. Gopakumar, and Leopoldo G. Franquelo, "Extended Linear Modulation Operation of Common-Mode-Voltage-Eliminated Cascaded Multilevel Inverter With a Single DC Supply”, IEEE Tran. on Ind. Elec., Vol. 63, No. 12, pp.7372-7380, December 2016.

38. Kehu Yang, , Zhibao Yuan, Ruyi Yuan, Wensheng Yu, Jiaxin Yuan, and Jin Wang, "A Groebner Bases Theory-Based Method for Selective Harmonic Elimination”, IEEE Tran. on Power Elec., Vol. 30, No. 12, pp. 6581-6592 December 2015.

39. L. Yu, H. Hoon, and A. Q. Huang, "Real-time calculation of switching angles minimizing THD for multilevel inverters with step modulation," IEEE Trans. Ind.Electron., Vol. 56, No. 2, pp. 285-293, Feb. 2009.

40. J. Lakwal, M. Dubey, "Modelling and Simulation of a Novel Multilevel Inverter for PV System using Unequal DC Sources", 2014 IEEE International Conference on Advanced Communication Control and Computing Technologies (ICACCCT), pp. 296-300, May. 2014.

41. N. A. Rahim, J. Selvaraj, and C. Krismadinata, "Five-level inverter with dual reference modulation technique for gridconnected PV system," Renewable Energy, Vol. 35, No. 3, pp. 712-720, Mar. 2010.

42. FengjiangWua, Xiaoguang Li a, Fan Feng b, HoayBengGooi b, "Efficiency enhancement scheme of cascaded multilevel gridconnected inverter and its improvement to eliminate effect of non-ideal grid conditions", Electrical Power and Energy systems Vol no.76, pp. 120-128, October 2016.

43. N. A. Rahim, M. F. M. Elias, and H. Wooi Ping, "Transistor-clamped H-bridge based cascaded multilevel inverter with new method of capacitor voltage balancing," IEEE Trans. Ind. Electron. , Vol. 60, No. 8, pp. 2943-2956, Aug. 2013. 

